\title{
Doppler microembolic signals during cardiac surgery: Comparison between arterial line and middle cerebral artery
}

\author{
Dimitrios Georgiadis, MD, ${ }^{a}$ Antonia Hempel, ${ }^{a}$ Ralf W. Baumgartner, MD, ${ }^{b}$ and Hans-Reinhard Zerkowski, MD, ${ }^{c}$ \\ Halle/Saale, Germany, and Zurich and Basel, Switzerland
}

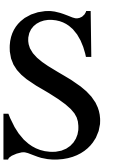

everal studies have demonstrated that the counts of Doppler microembolic signals (MESs) detected during cardiac surgery are related to (1) outcome and length of hospital stay, ${ }^{1}(2)$ degree of postoperative neuropsychologic deficit, ${ }^{2}$ and (3) incidence of new ischemic lesions on magnetic resonance imaging of the brain. ${ }^{3}$ Extracorporeal oxygenation causes varying amounts of air to be diluted in the blood; this air is only partially removed by the arterial filters that are routinely used. We undertook this study to evaluate (1) the percentage of MES reduction caused by the arterial filter and (2) the proportion of MESs actually reaching the brain, by comparing the MES counts detected before the arterial filter, after the arterial filer and in both middle cerebral arteries (MCAs).

\section{Patients and Methods}

Eleven patients, 7 men and 4 women aged $59 \pm 18$ years, were monitored during elective cardiac surgery (coronary artery bypass grafting $\mathrm{n}=9$, valve replacement $\mathrm{n}=2$ ). Anesthesia was induced by fentanyl and midazolam and maintained with fentanyl, midazolam, and isoflurane. Pancuronium was used for neuromuscular blockade. The $\mathrm{pH}$ was maintained by the alpha-stat strategy. Surgery was performed under normothermic bypass $\left(35^{\circ} \mathrm{C}-37^{\circ} \mathrm{C}\right)$. Blood aspirated from the surgical field was subsequently reinfused to the patient. A nonpulsatile blood flow pump (Stöckert S 3; Stöckert Instrumente $\mathrm{GmbH}$, Munich, Germany) and two membrane oxygenators (COBE CML Duo; COBE Cardiovascular, Inc, Arvada, Colo; DIDECO D 703 Compactflo; Dideco SpA, Mirandola, Italy) with tubing systems that included an arterial line filter (40 $\mu \mathrm{m}$; COBE) were used in all patients.

Both MCAs were continuously insonated at a depth of 52 to 58 $\mathrm{mm}$ for the complete duration of cardiopulmonary bypass (from skin incision until the end of the reperfusion period) in the presence of an experienced observer with two fixed 2-MHz transducers of a pulsed-wave transcranial Doppler machine (Multi-Dop X-4; DWL, Singen, Germany). Additionally, the arterial line of the

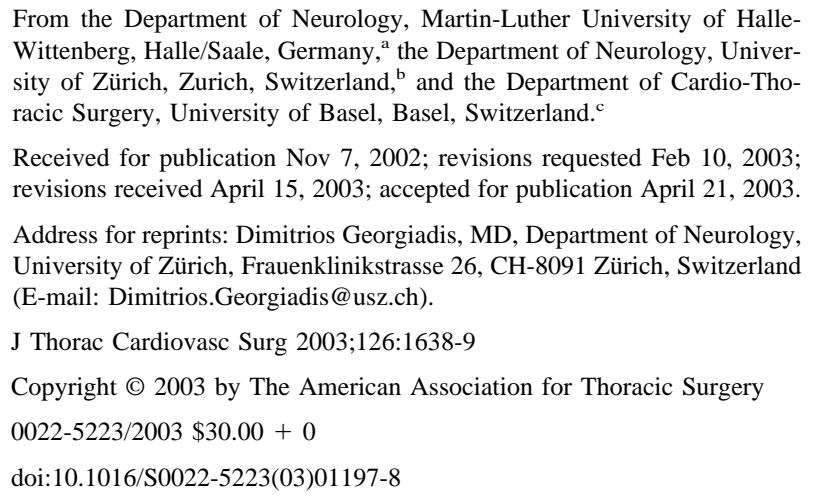

oxygenator was continuously monitored with two further $2-\mathrm{MHz}$ transducers with a sample volume of $10 \mathrm{~mm}$. These were inserted in a tubing device, assuring their stable placement and a constant distance between the transducer and the arterial line $(5 \mathrm{~cm})$. The space between the transducer and the tubing was filled with ultrasonic gel. Exact details of this monitoring procedure have been published elsewhere. ${ }^{4}$ All ultrasonographic data were recorded on digital audio tapes with an 8-channel digital audio recorder (TASCAM DA 88; TEAC Deutschland GmbH, Wiesbaden, Germany) for later reevaluation.

MESs were detected according to the following criteria: intensity increase at least $6 \mathrm{~dB}$ above background, characteristic acoustic qualities, and unidirectionality of signal. Evaluation of MESs was only performed during extracorporeal circulation. It was initiated after cannulation and clamping of the ascending aorta and terminated shortly before the aortic clamp was removed.

Nonnormally distributed data are expressed as medians with 95\% confidence intervals and compared with the Mann-Whitney $U$ test.

\section{Results}

The exact MES counts detected in each patient are listed in Table 1. The arterial filter resulted in a $58.9 \%$ reduction of MESs $(59132$ of 100394). Only 4.4\% (2624 of 59132) of the MESs detected after the arterial filter were actually detected in the MCAs. No significant differences in MES counts were observed when comparing the results of the right MCA with those of the left MCA $(P=.95$, Mann-Whitney test; Table 1).

\section{Discussion}

Our study produced two major findings: (1) the arterial filter resulted in a $60 \%$ reduction of MESs and (2) only approximately $4 \%$ of MESs that crossed the arterial filter finally reached the MCAs. The proportion of MESs detected in the MCAs corresponds to the total cerebral perfusion under cardiopulmonary bypass, as this is estimated as $5 \%$ to $10 \%$ of the total perfusion volume. Furthermore, the mean number of MES detected in the MCAs in this study (163, 95\% confidence interval 52-452) is comparable with the data reported by Barbut and colleagues ${ }^{5}$ (mean MES counts of $133 \pm 28$ ) during unilateral TCD monitoring over the MCA of 20 patients undergoing elective cardiac surgery.

Obviously, a main limitation of this study is our inability to distinguish between formed and gaseous embolic material. Unfortunately, such distinction was not feasible as our study commenced. A further study limitation was the low number of examined patients. It must be pointed out though, that a total of 162,150 MESs were analyzed. Because the purpose of this study was the evaluation of MESs associated with cardiopulmonary bypass, we 
TABLE 1. MES counts detected in 11 patients during cardiopulmonary bypass

\begin{tabular}{|c|c|c|c|c|c|c|c|c|}
\hline \multirow[b]{2}{*}{ Case } & \multirow[b]{2}{*}{$\begin{array}{c}\text { Age } \\
\text { (y) }\end{array}$} & \multirow[b]{2}{*}{ Sex } & \multirow[b]{2}{*}{ Bypass time (min) } & \multicolumn{5}{|c|}{ MES counts } \\
\hline & & & & Before filter & After filter & $\begin{array}{l}\text { Right } \\
\text { MCA }\end{array}$ & $\begin{array}{l}\text { Left } \\
\text { MCA }\end{array}$ & $\begin{array}{l}\text { Both } \\
\text { MCAs }\end{array}$ \\
\hline 1 & 69 & $\mathrm{~F}$ & 70 & 9258 & 6768 & 8 & 6 & 14 \\
\hline 2 & 44 & $\mathrm{M}$ & 67 & 5458 & 3469 & 97 & 148 & 245 \\
\hline 3 & 15 & $M$ & 65 & 6569 & 4610 & 462 & 389 & 851 \\
\hline 4 & 56 & $\mathrm{M}$ & 72 & 7933 & 4643 & 530 & 157 & 687 \\
\hline 5 & 70 & $\mathrm{~F}$ & 60 & 17,564 & 8091 & 160 & 126 & 286 \\
\hline 6 & 73 & $M$ & 75 & 4395 & 2363 & 23 & 29 & 52 \\
\hline 7 & 60 & $\mathrm{M}$ & 68 & 1683 & 1323 & 12 & 24 & 36 \\
\hline 8 & 66 & $M$ & 79 & 5315 & 1868 & 73 & 54 & 127 \\
\hline 9 & 49 & $\mathrm{~F}$ & 64 & 8088 & 2678 & 28 & 52 & 80 \\
\hline 10 & 78 & $\mathrm{M}$ & 55 & 26,230 & 18,458 & 31 & 15 & 46 \\
\hline 11 & 72 & $\mathrm{~F}$ & 110 & 7901 & 4861 & 102 & 98 & 200 \\
\hline \multicolumn{9}{|l|}{ Total } \\
\hline Sum & & & & 100,394 & 59,132 & 1526 & 1098 & 2624 \\
\hline Median & & & & 7343 & 4588 & 85 & 81 & 163 \\
\hline $95 \%$ Confidence interval & & & & $4927-15,132$ & $2668-9890$ & $26-279$ & 29-197 & $52-452$ \\
\hline
\end{tabular}

refrained from further evaluating MESs detected during other operation stages. Our study thus can provide no information on the relation between MES counts and various stages of cardiac surgery or surgical manipulations, because the MESs detected in this study were not caused by surgical interventions but solely by the oxygenator.

\section{References}

1. Barbut D, Lo YW, Gold JP, Trifiletti RR, Yao FS, Hager DN, et al. Impact of embolization during coronary artery bypass grafting on outcome and length of stay. Ann Thorac Surg. 1997;63:998-1002.

2. Harrison MJ, Pugsley W, Newman S, Paschalis C, Klinger L, Treasure
$\mathrm{T}$, et al. Detection of middle cerebral emboli during coronary artery bypass surgery using transcranial Doppler sonography [letter]. Stroke. 1990;21:1512.

3. Sylivris S, Levi C, Matalanis G, Rosalion A, Buxton BF, Mitchell A, et al. Pattern and significance of cerebral microemboli during coronary artery bypass grafting. Ann Thorac Surg. 1998;66:1674-8.

4. Georgiadis D, Wenzel A, Lindner A, Zerkowski HR, Zierz S. Influence of transducer frequency on Doppler microemboli signals in an in vivo model. Neurol Res. 1998;20:198-200.

5. Barbut D, Yao FS, Hager DN, Kavanaugh P, Trifiletti RR, Gold JP. Comparison of transcranial Doppler ultrasonography and transesophageal echocardiography to monitor emboli during coronary artery bypass surgery. Stroke. 1996;27:87-90.

\section{Should HIV-positive recipients undergo heart transplantation?}

Gianluigi Bisleri, MD, Jeffrey A. Morgan, MD, Mario C. Deng, MD, Donna M. Mancini, MD, and Mehmet C. Oz, MD, New York, NY

From the Department of Surgery, Division of Cardiothoracic Surgery, College of Physicians and Surgeons, Columbia University, New York, NY.

Received for publication June 21, 2003; accepted for publication July 14, 2003.

Address for reprints: Jeffrey A. Morgan, MD, Columbia University, College of Physicians and Surgeons, 177 Fort Washington Ave, Milstein Hospital 7GN-435, New York, NY 10032 (E-mail: jm2240@columbia. edu).

J Thorac Cardiovasc Surg 2003;126:1639-40

Copyright $\odot 2003$ by The American Association for Thoracic Surgery $0022-5223 / 2003 \$ 30.00+0$

doi:10.1016/S0022-5223(03)01216-9 everal centers have reported successful midterm results in HIV-positive patients who have undergone solid-organ transplantation. ${ }^{1,2}$ These reports have generally been limited to hepatic and renal transplantation. However, Calabrese and colleagues ${ }^{3}$ recently described a case of an HIVpositive patient who underwent successful orthotopic cardiac transplantation with midterm follow-up. The aim of this report is to describe another case of successful cardiac transplantation in an HIV-positive patient.

\section{Clinical Summary}

Our patient was a 42-year-old man with a 4-year history of HIV without any previous opportunistic infections. The patient had idiopathic cardiomyopathy with an ejection fraction of $10 \%$ and a history of multiple admissions for New York Heart Association 